\title{
Morpho-functional Features in Adolescent Males under Iodine Deficiency of the Saratov Region
}

\author{
Aleksey Popovsky, ${ }^{1)}$ Roman Kireev ${ }^{1)}$ and Irena Khomyakova ${ }^{2)}$ \\ 1) Biological Faculty of Saratov State University, Russia \\ 2) Institute and Museum of Anthropology, Moscow State University, Moscow, Russia
}

\begin{abstract}
An auxological study of 538 adolescent males (from 12 to 17) from different settlements of the Saratov region with various degrees of industrialization and iodine deficiency was carried out. All subjects have undergone an ultra-sound screening of thyroid volume to reveal the frequency of endemic goiter in each group. The results obtained during investigation showed the existence of deviations in the physical development of boys with goiter in skinfold thickness, body circumferences (chest, shoulder, and forearm), biacromial and biiliocristal diameters, transversal and sagittal chest diameters, body height and weight, BMI, leg length, and corpus length, all of which are greater in healthy adolescents $(\mathrm{SD}=1.0, p=0.000)$. In 46 subjects with endemic goiter, characteristics of metabolic status were investigated by the method of registration of endogenous intoxication (Malakhova, 1995). In comparison to the control group, a 1.2 times lower LAMM level in erythrocytes $(p<0.05)$ and 1.1 in urine $(p<0.05)$, and an increase by 2.3 in the LAMM level in blood plasma $(p<0.01)$ were detected. The relative percentage of catabolic substances exceeded the control values by 3.2 $(p<0.001)$. The OP level in erythrocytes is reduced by 2.2 $(p<0.01)$, in urine $(p<0.01)$ by 8.4 . The OP level is higher in plasma by $3.0(p<0.01)$. The adolescents with endemic goiter have a reallocation of protein matter between erythrocytes, plasma and urine. The spectrogram of erythrocytes shows lowering metabolites on membrane frames, which testifies to the destruction of the structurally functional properties of erythrocytes, and a lowering of absorption properties in glycocalix erythrocytes. J Physiol Anthropol Appl Human Sci 24(4): 407-411, 2005 http://www.jstage.jst.go.jp/browse/jpa

[DOI: $10.2114 /$ jpa.24.407]
\end{abstract}

Keywords: endemic goiter, morpho-functional status, endogenous intoxication, substances with low and average molecular mass (LAMM), oligopeptides (OP)

\section{Introduction}

Somatic development in children and adolescents, being one of the essential characteristics of child health, reflects an overall picture of the socio-economic and sanitary conditions of life of different population groups. Numerous investigations have proved the presence of morphological differences among groups of children living in different ecological zones and in cities with different levels of urbanization. This research equally comprises both extreme pollution by industrial products (Krstevska-Konstantinova et al., 2001; Teilmann et al., 2002; Rogan and Ragan, 2003; Rockett et al., 2004) and deficit or excess of microelements in the biosphere (Sheplagina,1999), caused by natural phenomena.

Iodine deficiency (ID) and thyroid gland disorders, provoked by this factor, at present establish a wide range of ecological and medico-social problems all over the world (Gaitan and Dunn, 1992; Delange, 2003) including the territory of Russia (Dedov et al., 2000).

The highest risk in acquiring pathological manifestations is observed in children and adolescents inhabiting iodinedeficient regions (Boyages, 1993; Baranov and Cheplagina, 1998). The most obvious changes in the thyroid gland take place in the puberty period as a response to the increased demand of the thyroid hormones of growing children (Dunn; 1998; Dedov et al., 2000; Fleury et al., 2001).

In spite of data concerning the negative influence of iodine deficiency upon the health of adolescents up till now, the regional peculiarities of physical development and sexual maturation in adolescent males have still not been sufficiently investigated, particularly in reference to groups inhabiting iodine-deficient regions.

\section{Subjects and Methods}

\section{Subjects}

538 adolescent boys from 12 to 17 years of age from different towns and cities of the Saratov region (Table 1) in connection with the condition of iodine deficiency disorders 
Table 1 Characteristics of investigated localities

\begin{tabular}{|c|c|c|c|}
\hline Population & 15,000 & 220,000 & $1,000,000$ \\
\hline $\begin{array}{l}\text { Level of } \\
\text { industrialization }\end{array}$ & low & high & high \\
\hline $\begin{array}{l}\text { Conditions } \\
\text { of ID }\end{array}$ & severe & moderate & mild \\
\hline
\end{tabular}

have been investigated.

Research studies of growth and development were carried out in different settlements of the Saratov district in 20022004. All subjects were attending a public secondary school. In 46 subjects aged 13-16 years from Khvalynsk a biochemical analysis for estimation of the metabolic status was carried out.

\section{Methods}

\section{Anthropometric measurements}

The program included about 16 anthropometric measurements, evaluation of developmental stages of secondary sexual characteristics - nipple growth (C), axillary $(\mathrm{Ax})$, pubic $(\mathrm{P})$ and facial $(\mathrm{F})$ hair.

\section{Ultrasonography}

The screening of thyroid volume was conducted with the ultra-sound technique "Aloka SSD-500" scanner (Japan). The length (1), width (w), and depth (d) of each thyroid lobe (in centimeters) were measured on transverse and longitudinal scans. The volume (vol) of each lobe (in milliliters) was estimated by the modified formula of the rotation ellipsoid $(\mathrm{vol}=\mathrm{l} \cdot \mathrm{w} \cdot \mathrm{d} \cdot 0.479)$, as described by Brunn et al (1981). The thyroid volume was defined as the sum of the volumes of both lobes. Results were compared with the reference values recommended by WHO (2002) and the International Council for Control of Iodine Deficiency Disorders (ICCIDD).

\section{Endogenous intoxication}

The criteria of endogenous intoxication was the determination of substances with low and average molecular mass (LAMM) and oligopeptides (OP). The method consisted of precipitating the large-molecule particles of plasma $(\mathrm{Pl})$, erythrocytes (Er) and urea (Ur) by means of trichloroacetic acid solution $(150 \mathrm{~g} / \mathrm{l})$ and water solution in the zone of wavelength from 238 to $310 \mathrm{~nm}$ on the spectrophotometer. The registration of a spectrum in this wave zone allows the estimation of toxic products and more than 200 substances generated in a normal and pathological metabolism. This method allows the description of a state of metabolic organism status (Malakhova, 1995). The coefficients of an endogenous intoxication were calculated using the following formulas: $\mathrm{K}_{1}=\mathrm{LAMMpl} / \mathrm{LAMMer} ; \mathrm{K}_{2}=\mathrm{LAMMur} / \mathrm{LAMMpl}+$ LAMMer; $\mathrm{K}_{3}=$ OPur/(OPpl+OPer).

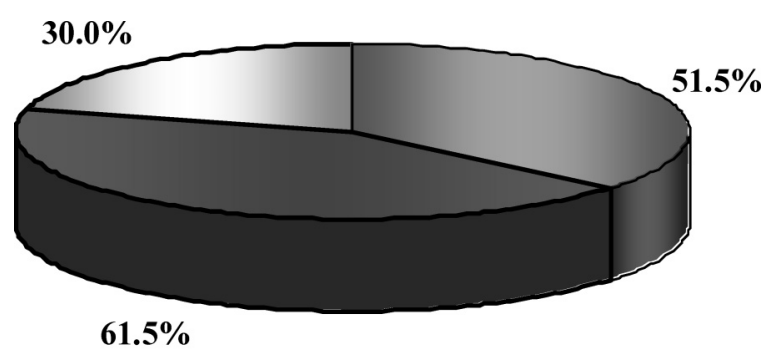

\section{$\square$ Khvalynsk $\square$ Saratov $\square$ Balakovo}

Fig 1 Frequency of endemic goiter in adolescent males of the Saratov region $(\%)$.

\section{Results}

Thyroid volume abnormalities were identified by ultrasonography in 263 adolescents and the results are summarized in Fig. 1.

Two groups of adolescent males were detected: with endemic goiter and a healthy group. Variations of anthropometric characteristics were analyzed as dependent on the degree of iodine deficiency disorders. For the analysis, all the data were standardized (Z-scores) and further comparisons were made irrespective of age groups. Significance of differences was assessed by one-way ANOVA.

Differences in anthropometric variations between the two groups can be observed. Healthy adolescents in all samples exceed their counterparts with endemic goiter. Because no significant difference was detected between groups from different cities, they were combined for further morphological analysis. The results show the existence of deviations in physical development of boys with goiter in skinfold thickness; circumferences of chest, shoulder, forearm; diameters (biacromial, biiliocristal, chest transversal and sagittal), body height and weight, BMI, leg length, and corpus length, all of which are greater in healthy adolescents $\mathrm{SD}=1.0, p=0.000$ (Fig. 2).

The comparative analysis of developmental stages of secondary sexual characteristics showed that adolescent males with endemic goiter have a slower rate of sexual maturation in all samples $(p<0.001)$. The Khvalynsk sample in comparison with the representatives of the two other groups have the latest periods of pubescence. Saratov boys occupy the leading 


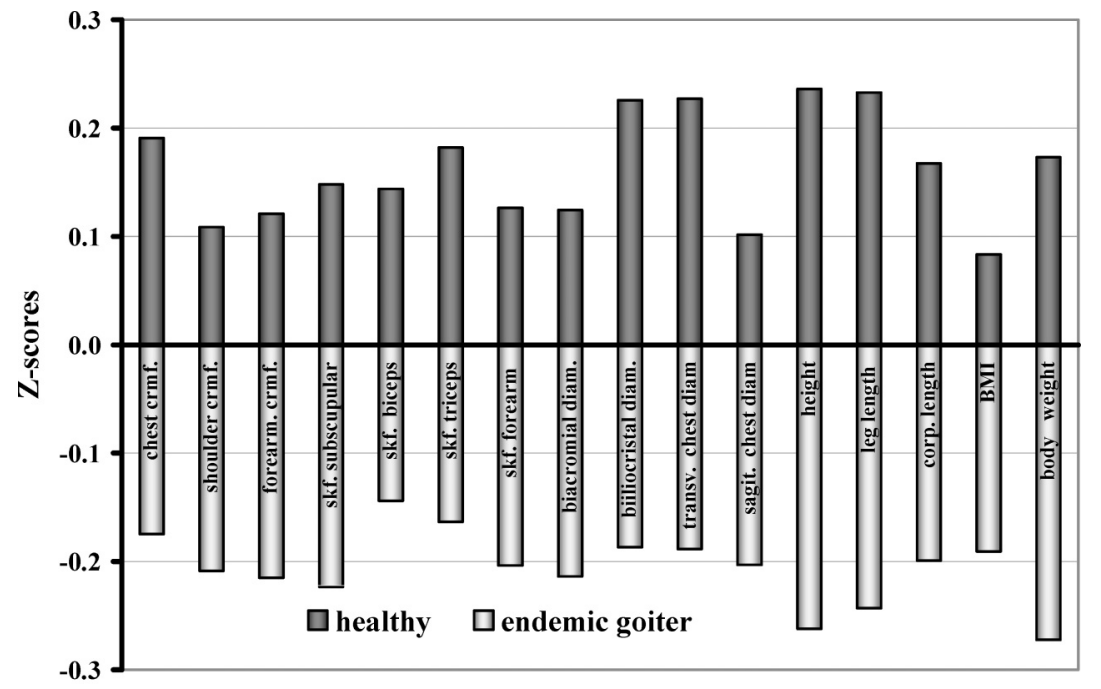

Fig. 2 Comparison of anthropometric characteristics in adolescent males from the Saratov region.

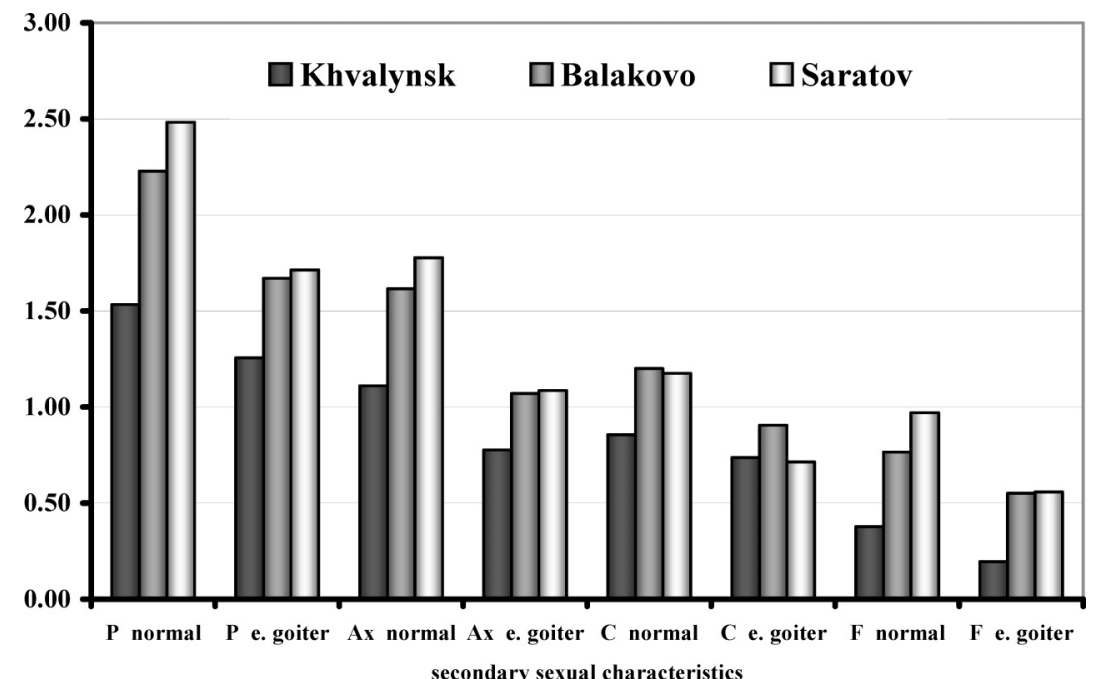

Fig. 3 Development stage of secondary sexual characteristics in adolescent males from the Saratov region.

position. However, significant differences were observed only between the children of the two groups in the degree of development stage $\mathrm{C}(p<0.05), \mathrm{P}(p=0.002), \mathrm{Ax}$ and facial hair $\mathrm{F}(p=0.000)$ as represented in Fig. 3.

In 46 subjects aged 13-16 years with endemic goiter from Khvalynsk, features of metabolic status were investigated by the technique of registration of endogenous intoxication by Malakhova (1995). For the control group, the data presented by Malakhova were used (Malakhova, 2000).

In the experimental group in comparison with the control, a low LAMM level in erythrocytes $(p<0.05)$ by a factor of 1.2 and in urine by $1.1(p<0.05)$, and an increase of LAMM level by a factor of 2.3 in blood plasma $(p<0.01)$ were detected. The comparative analysis of spectrograms between groups revealed the significant accumulation of the catabolic substances from plasma in adolescents with endemic goiter. The relation percentage of catabolic substances exceeded the values for the control group by a factor of $3.2(p<0.001)$.

High values of extinctions in waves lengths from 238, 242 and $246 \mathrm{~nm}$ on spectrograms of blood plasma, erythrocytes and urine testifies to the high content of uric acid, creatinine, and urea. In the control group these substances are undetectable. Marked deviations were probably connected with the disruption of nitrogen metabolism.

In comparison with the control group, the OP level in erythrocytes is reduced by $2.2(p<0.01)$, and in urine by 8.4 $(p<0.01)$. The OP level is higher in plasma by $3.0(p<0.01)$. The adolescents with endemic goiter have a reallocation of protein matter between erythrocytes, plasma and urine. Apparently, the high substratum contents of endogenous intoxication - substances with low and average molecular mass and oligopeptides in plasma - are caused by several factors.

In adolescent males with endemic goiter the spectrogram of erythrocytes shows lowering metabolites on membrane frames, 


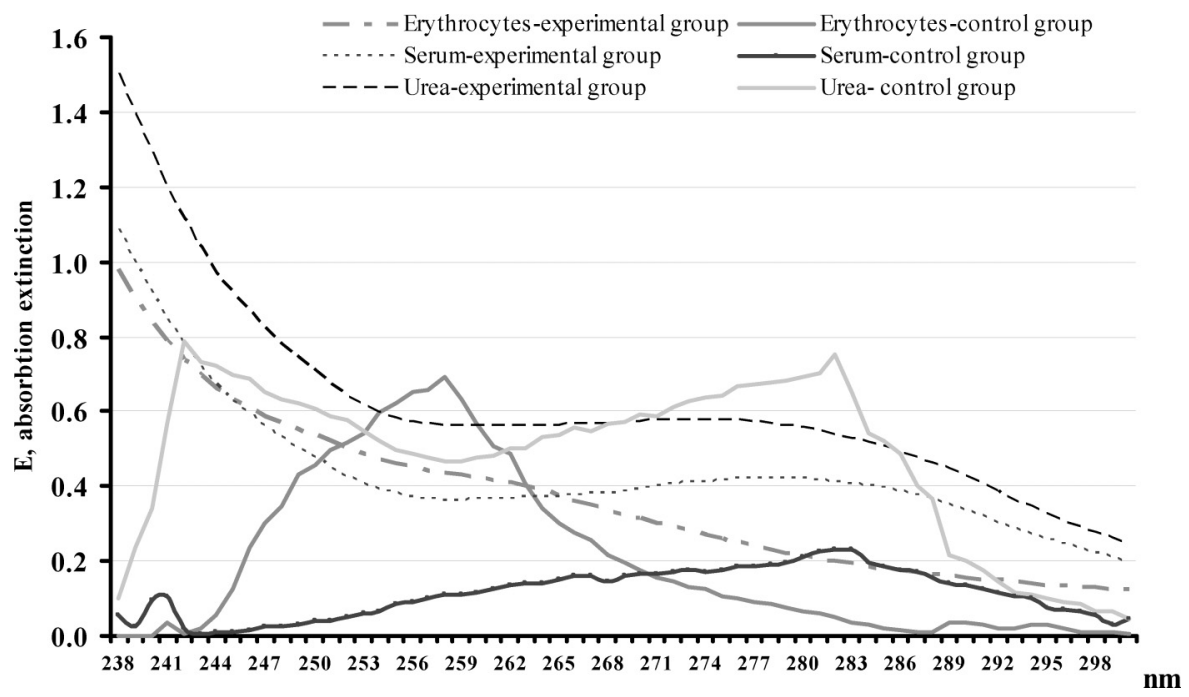

Fig. 4 Spectrograms of blood plasma, erythrocytes and urine of groups researched.

which testifies to the destruction of the structurally functional properties of erythrocytes and a lowering absorption properties in glycocalix erythrocytes, as $\mathrm{K}_{1}$ was higher by 2.7 times $(p<0.01)$ than in the control group. In addition, the LAMM and OP level in urine and coefficients $-\mathrm{K}_{2}, \mathrm{~K}_{3}$, describing elimination by the kidneys - were lower by 1.4 and 1.7 times $(p<0.001)$. Probably, there is poor renal elimination and hepatic detoxication of catabolic products.

Thus, the toxicogenic phase in adolescent males with endemic goiter is characterized by the presence of chronic endotoxication with expressed proteolysis (a high OP level in plasma), a course of metabolic responses mainly in catabolic paths, a decrease in the function of hepatic detoxication (a high LAMM and OP level in plasma) and of the kidneys (a low concentration of LAMM and OP in urine).

\section{Conclusion}

Results obtained during investigation of groups from different settlements of the Saratov district support the existence of deviations in the physical development of adolescent males with endemic goiter. Decrease of weightheight relations, decrease of body perimeters and fat layer, and slower puberty is detected.

The adolescent males with endemic goiter have disruptions of the reallocation of substances with average and low molecular mass between erythrocytes and plasma, which demonstrates the membrane changes in glycocalix erythrocytes. The detected increase in the contents of substances with low and average molecular mass and OP in plasma, the lowering of their concentration in erythrocytes and the reduced elimination of these substances may be explained by the disruption of functions in detoxication organs.

Acknowledgement The authors are grateful to Vadim Polyakov (Saratov State Medical University) for his help in the conducting of the ultra-sound study.

\section{References}

Baranov A, Cheplagina L (1998) Ecological and hygienic problems of children and adolescent health. Moscow, 218-234 [In Russian]

Boyages SC (1993) Iodine deficiency disorders. J Clin Endocrinol Metab 77: 587-591

Brunn J, Block U, Ruf G, Bos I, Kunze WP, Scriba PC (1981) Volumetrie der Schilddrüsenlappen mittels Real-timeSonographie. Dtsch Med Wochenschr 106: 1338-1340

Burgi H (1998) Hypothyroidism and puberty. In Pinchera A, Mann K, Hostalek U eds. The thyroid and age. Stuttgard, 171-177

Cheplagina L (1999) The problems of iodine deficiency. Russ Med J 7: 523-527 [In Russian]

Dedov I, Sviridenko I, Gerasimov G (2000) Estimation of iodine deficiency in the regions of Russia. Probl Endocrinol 46(3): 17-19 [In Russian]

Delange F (2003) How serious is iodine deficiency in Europe? Hot Thyroidology 3 (www.hotthyroidology.com)

Dunn JT, Dunn AD (1998) The thyroid and iodine. In Pinchera A, Mann K, Hostalek U eds. The thyroid and age. Stuttgart, 193-201

Gaitan E, Dunn J (1992) Epidemiology of iodine deficiency. Trends Endocrinol Metab 3: 170-175

John CR, Courtney DL, Germaine MB (2004) Biomarkers for Assessing Reproductive Development and Health: Part 1-Pubertal Development. Environ Health Perspect 112: $730-737$

Krstevska KM, Charlier C, Craen M, Du Caju M, Heinrichs C, de Beaufort C, Plomteux G, Bourguignon JP (2001) Sexual precocity after immigration from developing countries to Belgium: evidence of previous exposure to organochlorine pesticides. Hum Reprod 16: 1020-1026 
Malakhova M (2000) Endogenous intoxication as reflection of compensator modification of metabolic processes in an organism. Efferentnay terapia 4: 3-14 [In Russian]

Malakhova M (1995) Metabolic status of organism: methods of registration and clinical usage. Method of registration of endogenous intoxication. St-Petersburg, 1-35 [In Russian]

Svinaryov M, Aranovich V (2003) Iodine deficiency disorders in the Saratov province in Russia. J Endocrinol Invest 26 (2 Suppl): 9-16

Teilmann G, Juul A, Skakkebaek NE, Toppari J (2002) Putative effects of endocrine disrupters on pubertal development in the human. Best Pract Res Clin Endocrinol Metab 16: 105-121

Rogan WJ, Ragan BN (2003) Evidence of Effects of Environmental Chemicals on the Endocrine System in
Children. Pediatrics 112: 247-252

World Health Organization, International Council for Control of Iodine Deficiency Disorders (2002) Recommended normative values for thyroid volume in children aged 6-15 years. Bull World Health Organ 75: 95-97

Yvan F, Guy VM, Virgile W, Rolf CG, Luc P (2001) The Endocrine Society Sex-Dependent Variations and Timing of Thyroid Growth during Puberty. J Clin Endocrinol Metabol 86: $750-754$

Received: March 25, 2005

Accepted: March 29, 2005

Correspondence to: Aleksey Popovsky, Biological Faculty, Saratov State University, 83 Astrakhanskaya, Moscow, Russia e-mail: popovskyL@mail.ru 